\title{
Improving tuberculosis surveillance in Europe is key to controlling the disease
}

L D’Ambrosio ${ }^{1}$, R Centis ${ }^{1}$, A Spanevello ${ }^{1,2}$, G B Migliori ${ }^{1}$

1. WHO Collaborating Centre for TB and Lung Diseases, Fondazione S. Maugeri, Care and Research Institute, Tradate, Italy

2. Universita’ degli Studi dell'Insubria, Varese, Italy

Citation style for this article: D’Ambrosio L, Centis R, Spanevello A, Migliori GB. Improving tuberculosis surveillance in Europe is key to controlling the disease. Euro Surveill. 2010;15(11): pii=19513. Available online: http://www.eurosurveillance.org/ViewArticle. aspx?Articleld=19513

This article has been published on 18 March 2010

DNA of Tuberculosis (TB) bacteria were found in mammoth bones and in Egyptian mummies and TB has affected mankind since its appearance, despite many efforts to control and eliminate it [1].

It was already well known since the sanatoria period (Germany, 1857) when treatment against TB consisted of good food, rest, sun, and fresh air that about half of TB cases recovered almost spontaneously. Robert Koch's discovery of Mycobacterium tuberculosis in 1882, Carlo Forlanini introduced the artificial pneumothorax in 1907 [1] and streptomycin was introduced at the end of the Second World War. These discoveries revolutionised the understanding and treatment of TB.

In spite of these discoveries, the epidemic trend has tended more towards an increase in recent years. The interventions recommended by the directly observed treatment, short-course (DOTS) and the Stop TB Strategy introduced in 2006 [2], e.g. rapid diagnosis of $70 \%$ of existing sputum smear-positive cases and effective treatment of $85 \%$ of them, are very powerful in reversing the epidemic trend. This was demonstrated in several countries, e.g. in Peru and recently in Europe: Romania achieved 70/85\% targets and, after an initial increase, was able to reduce both its case and case-fatality load [3].

Multidrug-resistant (MDR) and extensively drug-resistant (XDR) TB mainly emerge as the result of mismanagement of TB, either by the prescribing physician (regimen, dose, duration) or the patient (compliance). Failure of the programme contributes as well: poor quality drugs, lack of public health action in ensuring patient support and correcting early signs of sub-optimal patient management represented by late sputum smear and culture conversion, presence of failures, defaulters and avoidable deaths.

As underlined by the joint ECDC and World Health Organization Regional Office for Europe TB report, launched on 18 March [11] the importance of good surveillance to stem this trend cannot be underestimated.
Where do we go with surveillance in Europe? Can we do more? How many MDR and XDR TB cases occur because of sub-optimal patient management?

This issue of Eurosurveillance casts light on these important questions with four interesting articles [4-7].

A paper by Manissero et al. from the ECDC reports on surveillance data in twenty-two countries of the European Union (EU) and European Economic Area (EEA) done by the ECDC Tuberculosis Programme [4]. Treatment outcome monitoring was performed on culture-confirmed pulmonary TB cases reported in 2007 . While the overall treatment success rate was $73.8 \%$ (79.5\% among new cases), only three countries achieved the $85 \%$ success rate target as a result of high defaulting and a relevant proportion of unknown outcomes.

A surveillance report by Devaux et al. [5] describes retrospectively the results of second-line drug susceptibility testing (DST) among MDR TB cases reported in 20 countries of the WHO European Region (15 being EU countries) aimed at identifying XDR TB. In 18 countries (only) DST was performed for two or more of the second-line drugs defining XDR TB, with relevant intercountry variation on the proportion of isolated tested. Overall, $10 \%$ of the MDR TB strains are found to be XDR.

A report by Ködmön et al. [6] describes the surveillance data collected by ECDC from EU and EEA countries. In 2008 , the combined proportion of new and retreated MDR TB cases was $6.0 \%$ of the total case load for the 25 countries reporting data. Thirteen countries provided data on resistance to second-line drugs, allowing the identification of XDR TB cases. 68 XDR TB cases were reported in 2007 (6.1\% of the MDR TB cases) and 90 in 2008 (7.3\% of the MDR TB cases). Latvia and Romania notified the highest number of XDR TB cases in 2008.

Next is a surveillance report by Caley et al. on a retrospective cohort study performed in the UK to quantify the risk of developing TB infection or disease following school contact with an infectious student. The report results suggest that greater levels of classroom 
contact with a sputum smear positive student significantly increases the risk of contracting both active TB disease and latent TB infection.

The results of the studies reported in this issue of Eurosurveillance allow us to point out some key topics:

- The completeness of reporting information (including treatment outcomes), the proportion of culture-confirmed TB cases reported as well as the proportion of strains on which DST for both firstand second-line drugs is performed and reported are still sub-optimal overall in Europe. The relevance of these pitfalls goes beyond the "simple" surveillance limitation, having the potential to affect other important TB control pillars, e.g. infection control and case-management.

- MDR and XDR TB still persist in Europe. The high proportion of MDR TB identified among new TB cases reported by certain countries indicates that sub-optimal infection control practices are likely to occur, while the high percentage of MDR TB notified among retreatment cases is probably the result of sub-optimal case management in the past decade.

ECDC is managing surveillance of TB at the EU level in collaboration with national correspondents, WHO Regional Office for Europe and partners. The joint ECDC and World Health Organization Regional Office for Europe TB report, launched on 18 March, shows that tuberculosis is still a matter of concern in Europe. Tuberculosis Surveillance in Europe 2008 presents the latest data on TB cases and shows that the decline in cases has slowed down [11].

With the enhanced and improved regular surveillance of anti-TB drugs and molecular surveillance of MDR TB cases, ECDC is offering an added value to the European surveillance $[9,10]$. Surveillance is an integral part of TB control, its contribution being essential to inform the programme on what is going on and what public health response is urgently needed. Investing in better "intelligence" is a pre-requisite to improve TB prevention and control in Europe, in order to reach the elimination goal for Europe committed to in the early $1990 \mathrm{~s}$ [8].

\section{References}

1. Migliori GB, Sotgiu G, Lange C, Centis R. XDR-TB: back to the future. Eur Respir J. 2010; in press.

2. Raviglione MC, Uplekar MW. WHO's new Stop TB Strategy. Lancet. 2006;367(9514):952-5.

3. Marica C, Didilescu C, Galie N, Chiotan D, Zellweger JP, Sotgiu $G$, et al. Reversing the tuberculosis upwards trend: a success story in Romania. Eur Respir J. 2009;33(1):168-70.

4. Manissero D, Hollo V, Huitric E, Ködmön C, Amato-Gauci A. Analysis of tuberculosis treatment outcomes in the European Union and European Economic Area: efforts needed towards optimal case management and control. Euro Surveill. 2010;15(11). pii=19514. Available online: http://www. eurosurveillance.org/ViewArticle.aspx?Articleld=19514

5. Devaux I, Manissero D, Fernandez de la Hoz K, Kremer K, van Soolingen D, on behalf of the EuroTB network. Surveillance of extensively drug-resistant tuberculosis in Europe, 2003-2007.
Euro Surveill. 2010;15(11). pii=19518. Available online: http:// www.eurosurveillance.org/ViewArticle.aspx?Articleld $=19518$

6. Ködmön C, Hollo V, Huitric E, Amato-Gauci A, Manissero D. Multidrug- and extensively drug-resistant tuberculosis: a persistent problem in the European Union European Union and European Economic Area. Euro Surveill. 2010;15(11). pii=19519. Available online: http://www.eurosurveillance.org/ViewArticle. aspx?Articleld=19519

7. Caley M, Fowler T, Welch S, Wood A. Risk of developing tuberculosis from a school contact: retrospective cohort study, United Kingdom, 2009. Euro Surveill. 2010;15(11). pii=19510. Available online: http://www.eurosurveillance.org/ViewArticle. aspx?Articleld $=19510$

8. Broekmans JF, Migliori GB, Rieder HL, Lees J, Ruutu P, Loddenkemper R, Raviglione MC; World Health Organization, International Union Against Tuberculosis and Lung Disease, and Royal Netherlands Tuberculosis Association Working Group. European framework for tuberculosis control and elimination in countries with a low incidence. Recommendations of the World Health Organization (WHO), International Union against Tuberculosis and Lung Disease (IUATLD) and Royal Netherlands Tuberculosis Association (KNCV) Working Group. Eur Respir J. 2002;19(4):765-75.

9. Falzon D, Infuso A, Aït-Belghiti F. In the European Union, TB patients from former Soviet countries have a high risk of multidrug resistance. Int J Tuberc Lung Dis. 2006;10(9):954-8.

10. Devaux I, Kremer K, Heersma H, Van Soolingen D. Clusters of multidrug-resistant Mycobacterium tuberculosis cases, Europe. Emerg Infect Dis. 2009;15(7):1052-60. This project applied to MDR TB only. The new dimension with ECDC is to apply molecular surveillance to all TB cases.

11. European Centre for Disease Prevention and Control/WHO Regional Office for Europe: Tuberculosis surveillance in Europe 2008. Stockholm, European Centre for Disease Prevention and Control, 2010. Available from: http://www.ecdc.europa. eu/en/publications/Publications/1003_SUR_tuberculosis surveillance_in_europe_2008.pdf 